\title{
Linking Root Words and Derived Forms for Adult Struggling Readers: A Pilot Study
}

\author{
Susan H. Gray, Bridgewater State University \\ The author would like to express gratitude to Dr. Linnea Ehri, Dr. Lorraine Obler, Dr. Martin Chodorow, and Dr. Jaye Jones \\ as well as to the teachers and students with whom she worked on this project.
}

\begin{abstract}
:
The goal of this pilot study was to investigate the effects of morphological instruction on component literacy skills of adult struggling readers. Sixteen adults, most with decoding and encoding deficits, were randomly assigned to tutoring in either morpheme or syllable analysis to learn academic vocabulary and increase component literacy skills. Those taught semantic connections between Latin and Greek root words and their derived forms outperformed those taught syllable types on a standardized test of word recognition, though both groups demonstrated large gains for learning target words. Results support connectionist theories that promote teaching morphological links in literacy instruction.
\end{abstract}

Ninety million adults in the United Stated have low literacy skills according to the National Research Council (2012). Given the number of people directly affected, and the associated costs to public health and employment, there is a serious lack of rigorous research studying interventions for adult struggling readers (Greenberg, 2008; Kruidener, 2002; Tighe \& Schatschneider, 2016). Adults seeking alternative high school credentials like the General Education Development (GED) diploma, and those in Adult Basic Education (ABE) programs have a wide range of reading skill deficits (Perin, Flugman \& Spiegal, 2006; Greenberg, Ehri \& Perin, 1997). Surprisingly, despite promising results of morphological instruction with both children and adults, there is little evidence that adult literacy studies are taking advantage of the potential of teaching morphemes, including prefixes, root words and suffixes (Alamprese, MacArthur, Price \& Knight, 2011; Deacon, Parrila
\& Kirby, 2006; Fracasso, Bangs \& Binder, 2015; Law, Wouters \& Ghesquiere, 2015). Randomized pilot studies such as this one, are "those in which a future definitive clinical trial involving randomized study groups or its components are investigated on a miniature scale" (Kaur, Figueiredo, Bouchard, Moriello \& Mayo1, 2017, p. 1243). This study tests the feasibility of providing instruction in morphemes to increase component literacy skills of adult struggling readers.

\section{Theoretical Underpinnings}

According to Perfetti and Hart's (2002) Lexical Quality Hypothesis, the process of reading is essentially about knowledge of words. Being able to reliably identify the pronunciations, spellings and meanings of words paves the way for successful reading comprehension and subsequently, more practice with reading. Perfetti and Hart (2002) 
argue that "multiple encounters with a given word tend to produce a common core representation consisting of a nexus of orthographic, phonological and semantic information" (p. 190). Skilled readers tend to have tightly connected internal representations of words' spellings, pronunciations and meanings. In contrast, struggling readers tend to have poorly specified lexical representations of words' core constituents such as their orthographic, phonological and semantic (with syntactic)

identities. Low quality lexical representations result in poor word analysis and word identification skills, impeding access to higher level skills like fluency and comprehension. Simply put, readers are not likely to comprehend passages containing words they cannot decode or recognize. Increasing the quality of lexical representations ought to lead to greater word reading, thereby reducing obstacles to comprehension (Perfetti, 2007).

Like Perfetti, Ehri $(1978,1999,2005)$ argues that readers must clearly specify words' phonological, semantic (with syntactic), and orthographic identities to read words fluently. Ehri (1999, 2005) theorizes that readers progress through various levels of linguistic awareness in learning sight words, which are defined as any words that readers can identify instantly. These levels of linguistic awareness include the pre-alphabetic, partial alphabetic, full alphabetic and consolidated alphabetic phases. In the first three phases, readers learn to map graphemes with phonemes with increasing proficiency. In the final stage, readers learn to read larger, "consolidated" linguistic units, such as morpheme and syllable units, which facilitates complex word reading by reducing the memory load (Ehri, 2005).

\section{The Potential of Teaching Morphemes to Adult Struggling Readers}

Many adults struggle to read complex words
(Greenberg, Ehri \& Perin, 1997; Perin, Flugman \& Spiegal, 2006; Tighe \& Binder, 2015), and require explicit instruction to read "consolidated" linguistic units. Teaching adults with low literacy to read larger "consolidated" units, including both morphemes and syllables, ought to be beneficial. Teaching them morphemes might even be more effective than teaching them syllables because it encompasses all three constituents (phonological, semantic and orthographic) required for high quality lexical representations, whereas teaching syllables encompasses only two constituents (phonological and orthographic). Furthermore, teaching syllables may encourage readers to "abstract away" from meaningful lexical boundaries within words, in order to focus on superficial phonological boundaries (Chomsky, 1970, p. 291). Consider how parsing the word question into its syllables ques and tion obscures the meaning of its morphemes quest and ion, and semantic links to its relatives such as request and conquest.

For older struggling readers, relatively stronger awareness of morphemes (morphological awareness) may offset severely reduced awareness of phonemes (phonological awareness). For example, middle school age students with reading disabilities who were given comprehensive literacy instruction with a morphological element showed greater literacy improvements than those in a phonological control group (Berninger, Nagy, \& Carlisle, 2003). Adult struggling readers often read at approximately middle school levels, with one study estimating that GED students' skills were just below the fifth-grade level (Perin, Flugman \& Spiegal, 2006). Thus, if morphological instruction boosts literacy in middle schoolers, it may also benefit adult readers with middle school level skills.

Four correlational studies show the critical role of both morphological awareness and phonological awareness in adult literacy, which makes sense given 
that the structure of English is morpho-phonemic. This means that English orthography reflects both words' phonemes (i.e., jump maps each sound to a letter) and morphemes (i.e., jumped retains the past tense morpheme as $e d$, even though it is pronounced as /t/) (Chomsky \& Halle, 1968). In the first study, Reilly and Binder (2013) evaluated the literacy skills of 293 adults in basic education. Component literacy skills were compared to three tasks of morphological awareness. For both native English and native Spanish speakers, morphological awareness correlated highly with vocabulary and comprehension, leading researchers to conclude that adults in basic education would benefit from direct teaching of morphemes. In the second study, Herman, Cote, Tighe \& Binder (2015) found that morphological awareness contributed independently and substantially to reading comprehension for adults with low literacy enrolled in Adult Basic Education (ABE) classes. The 57 adults in their study demonstrated difficulties reading complex words, for which authors recommended the teaching of prefixes, base words and suffixes. In the third study, Tighe and Schatschneider (2016) examined the component literacy skills of adult struggling readers, to weigh the relative contributions of each component skill to the process of reading comprehension. They analyzed 16 studies with 2,707 poor readers and identified 10 component reading skills that were consistently referenced, including both morphological and phonological awareness. Morphological awareness was one of six component reading skills most strongly correlated with reading comprehension, in addition to language comprehension, fluency, oral vocabulary decoding and working memory. In the fourth study, Fracasso, Bangs \& Binder (2016) found a strong influence of both morphological awareness and phonological awareness on the reading skills of adults in ABE. Phonological awareness predicted spelling, listening comprehension and reading comprehension, whereas morphological awareness predicted spelling, vocabulary and listening comprehension skills.

Beyond correlational studies, there is also evidence that morphological instruction benefits adult struggling readers. Alamprese et al. (2011) investigated the effects of a morpho-phonemic reading intervention program on the literacy skills of low to intermediate adult readers. Using a program based on Venezky's (1999) study of English orthography, students were taught a structured approach to word analysis that focused on phonemes, morphemes and spellings, as well as a metacognitive strategy for decoding complex words. Those who received the structured approach made better gains in decoding than those in the control group, who were taught the regular adult literacy program using a children's curriculum adapted for adult use, but both groups made small to moderate gains in word recognition and spelling. Similarly, Gray, Ehri and Locke (2018) taught GED students to analyze the word origins, base words, morphemes and syllables of academic vocabulary words embedded within a civics curriculum. Those taught to parse words' morpheme and syllable structures made greater word reading gains than those taught the same words as whole words, without analyzing their internal structures. Thus, adult literacy instruction that draws attention to the phonemes, morphemes and spellings of complex words results in literacy gains, particularly for word recognition.

\section{The Importance of Academic Vocabulary for Adult Struggling Readers}

Academic language is the formal, specialized language, both spoken and written, that occurs within academic settings to facilitate thinking about advanced concepts and disciplinary content (Nagy \& Townsend, 2012). It serves a purpose, in 
which "the grammatical attributes of academic language- more affixed words, nouns, adjectives, prepositions, and nominalizations-are means of achieving greater informational density and abstractness" (p. 93). Academic vocabulary words tend to be morphologically complex, with base words extended through suffixes that are either inflectional (i.e., do not change the part of speech of a word, as motive and motives) or derivational (i.e., do change the part of speech, as in motive and motivational). Academic text contains many multi-morphemic words, many of which come from the Latinate layer of English, with its characteristic bound roots that require additional word parts, such as prefixes and affixes, to stand alone as words. For example, the bound root agri, meaning field, is seen in the derived forms agriculture and agrarian (Moats, 2010, p.122.).

Recent changes in proficiency tests for adults, such as the revised GED, the HiSET and WIOA, require comprehension of more sophisticated and discipline specific texts for which morphological instruction could be advantageous. For example, science tests that contain numerous Latinate vocabulary words ought to support students in passing the proficiency tests and succeeding in post-secondary education. According to Adams (2015), the new GED test is "designed to be more challenging, with questions that focus on critical thinking and better reflect new standards for career and college readiness" (p. 4). Teaching academic vocabulary through morphological instruction offers advanced instruction for the more rigorous test.

\section{Linking Academic Vocabulary to Bound Root Words}

Recent research has demonstrated the effectiveness of teaching middle and secondary school students about word parts from the Latinate layer of English, specifically bound root words that require other word parts like prefixes and suffixes to stand alone as complex words. One study demonstrates the effectiveness of teaching bound root words to older children to promote use of a word-learning strategy that Anglin (1993) called "morphological problemsolving” (Crosson \& McKeown, 2016; Crosson \& Moore, 2017). In his seminal study measuring children's vocabulary growth, Anglin differentiated "actually learned" words from "potentially knowable" words, the latter of which were greatly increased by knowledge of "morphological problem-solving”. Children demonstrated "knowledge of a morphologically complex word by relating it to another complex word of similar morphological form (e.g., if a piglet is a baby pig, then 'a treelet might be a baby tree')" (p. 144, 145). Crosson and McKeown (2016) asked whether explicit teaching of bound morphemes would increase middle schoolers' ability to infer meanings of unfamiliar academic vocabulary. They taught morphological analysis directly, first by providing students with the root word origin and its meaning, then by showing them how to analyze connections between the bound root word and its root-related words. For example, the bound root word $\mathrm{min}$ meaning small connects the word diminish to minor. Dynamic assessment revealed that sixth and seventh graders who were taught morphological analysis demonstrated a significantly greater ability to infer meaning for root related words than the control group who received the regular language arts instruction. They noted that "instruction in bound roots might strengthen mental representations for the instructed words by providing more connections about a word's semantic and orthographic features" (p. 168). Given that adult struggling readers often have middle school reading levels, perhaps the instruction of bound roots that was effective for middle schoolers could be successful with adults as well. 


\section{Rationale for Current Study}

The morphological intervention of this pilot study adhered to the principles that were effective in Kieffer and Lesaux's (2010) morphological instruction for adolescents who had approximately the same reading levels as the adults in the current study. First, systematic teaching of morphemes with flexible stems was accomplished through instruction in root word trees, which were graphic organizers displaying high frequency root words in the root position of trees and low frequency derived forms in the branches of the trees. Second, teaching a cognitive-linguistic strategy was achieved through instruction in morphemic analysis and circling of Latin or Greek root words within their derived forms. These principles were also consistent with Crosson and McKeown's (2016) study teaching meanings of bound root words to middle schoolers to increase their ability to infer the meanings of unfamiliar words.

The control phonological intervention taught six syllable types which are often used in effective phonics instruction (Duff, Stebbins, Stormont, Lembke, \& Wilson, 2016) particularly with students who have decoding difficulties (Mather \& Wendling, 2011): closed syllables (lax vowel sound followed by consonant sound/s; e.g. cat); vowelconsonant-E syllables, (tense vowel sound followed by consonant and final silent E e.g. pine); open syllables (tense vowel sound at end; e.g., ro-bust); consonant -LE syllables (consonant followed by LE; e.g., mar-ble); r-controlled syllables (contain vowel sound followed by R; e.g., car); and double vowel, schwa and odd syllables (contain consecutive vowels pronounced as one or two sounds; e.g., soap, boil; unstressed reduced vowel sounds; e.g. $a$-bout; and structures not categorized as any of the other five syllable types) (Moats, 2010).

Best practice for pilot studies asserts that they "can be used to evaluate the feasibility of recruitment, randomization, retention, assessment procedures, and implementation of the novel intervention and each of these can be quantified" (Leon, David \& Kraemer, 2010, p. 626). In accordance with the criteria for randomized pilot studies, this study addressed the following questions: Were recruitment, randomization, and retention of participants successful? Was the experimental intervention effective and its control condition suitable? Does this pilot study demonstrate the potential for a successful randomized control trial?

\section{Method}

\section{Participants}

Four ABE and 13 GED students volunteered to participate by signing up during classes at an adult learning center in New York City. Participants met the eligibility criteria: enrollment in a GED program ( $\mathrm{m}=10^{\text {th }}$ grade education); native English speaker or bilingual English/Spanish from birth (10 monolingual; 6 bilingual); age of 18-30 $(\mathrm{m}=23)$; at least average intelligence (TONI-4 Index $\geq 85$ ); and no reported history of cognitive, neurological, sensory or speech-language disorder. Seven were Hispanic, four were Indian-American, and five were African American. Of the 12 females and four males, half were employed in minimumwage jobs, such as childcare, sales, and food service. Their reading skills ranged from $4^{\text {th }}$ to $10^{\text {th }}$ grade equivalency levels, with sixth grade skills on average. All demonstrated significantly reduced performance on at least one component literacy skill; all had reduced word attack except one who had reduced comprehension. Seventy-five percent reported that they had never received specialized literacy instruction in school. 


\section{Materials}

\section{Standardized Measures}

To screen for intelligence, participants completed the Test of Nonverbal Intelligence (TONI-4), a pattern recognition task (Brown, Sherbenou \& Johnsen, 2010). To estimate reading levels for random assignment to treatment, reading composites were calculated using the mean grade equivalency of the WJ-III. Split-half reliabilities for the 19-29-year-old norm group appear in parentheses: Letter Word Identification, an oral word reading task ( $r=.90-.91)$; Reading Vocabulary, requiring production of synonyms, antonyms and analogies after reading words $(r$ $=$.87-.91); and Passage Comprehension, a silent reading, sentence completion task $(r=.75)$

(Woodcock, McGrew \& Mather, 2001, 2007). Using the reading composites, participants were ranked, matched in pairs, and randomly assigned to either intervention. WJ-III decoding and encoding subtests were not included in the reading composites due to participants' very low scores but were included as pretest/posttest measures: Word Attack, a pseudoword reading task $(r=.83-.87)$, 5) Spelling, a word dictation test $(r=.88-.91)$, and 6) Spelling of Sounds subtest, a pseudoword dictation task $(r=.58-.64)$. Alternate WJ-III forms were used at pretest (A) and post-test (B) with high correlation $(r=.85$ - .96) (McGrew, Schrank \& Woodcock, 2007).

\section{Target Word Measures}

Five target word measures assessed participants' gains within each session: Target Word Identification (Task: Read target words. Example: edict.); Target Word Analysis (Task: Circle target words' roots. Example: circling dict in dictum.); Target Word Spelling (Task: Spell target words to dictation. Example: malediction); Target Word Definition Matching (Task: Match target words to their definitions. Example: benediction is matched with a blessing.); and Target Word Sentence Completion (Task: Complete sentences using target words. Example: A local rabbi started the ceremony by giving a to the audience. (answer: benediction).

\section{Intervention Programs}

Participants completed four weekly 2-hour sessions of intervention, plus 2 hours of testing. Each intervention included the following common elements: individual tutoring; PowerPoint slideshow presentation of about 400 slides; teaching the same 56 target words, using the same definitions (for definition matching task) and the same sentence contexts (for the sentence completion task); graphic organizers; and target word measures. Each participant had a binder containing: worksheets with the graphic organizers for each of the 56 target words and pretests and posttests for each of the 5 target word measures. In the first three sessions, four graphic organizers were taught (each with four academic vocabulary words) and in the final session, two graphic organizers were taught.

Target words were selected using a list of frequently occurring root words (high frequency, to promote learning transfer) (Frye \& Kress, 2006), and a list of their infrequently occurring derived forms (low frequency, to reduce the chances of teaching words that were already familiar to participants). Target words were morphologically and phonologically complex (2-4 morphemes, 2-6 syllables) low frequency words. Words, definitions and sentences were selected from a 9 - 12 grade vocabulary program (Osborne, 2003), dictionary and etymology websites.

\section{Morphemes Treatment}

Vocabulary words were organized in 14 sets of 
Latin/Greek root words, each with 4 derived forms, totaling 56 words. Graphic organizers for each set depicted a tree, whose roots contained the spelling and meaning of the high frequency root word, with branches containing the spellings and meanings of the 4 derived forms. To illustrate semantic connections between root words' and derived forms', definitions of the derived forms included the root word meaning. For example, the Latin root fic /fac, meaning make or do, was presented in the root position of the tree, with the 4 derived forms and their meanings (containing the root word meaning make) in the branches: artifact (an object made by man); fictitious (created by imagination; made up); facsimile (a copy, made alike); and malefactor (criminal, maker of something bad). See Figure 1.

For each root word set, tutors and participants read aloud from scripted slides instructing participants to: View a picture representing the meaning of the root word; View the root tree graphic organizer; Copy the content of the graphic organizer in their binders; Analyze the words' morphemes in the following ways: Listen to and repeat the word; Divide the word into morphemes, using hyphens; Underline the morpheme that is pronounced with the primary stress; Circle the root word; Write the spelling of the word after dictation; Match the word to its definition; and Complete the sentence using the derived word.

The sequence of instruction for morphological training was determined by the level of phonological transparency of derived forms. Effective morphological instruction begins with words that have transparent morphological relationships (Goodwin, 2010) without pronunciation changes from the root or base word to the derived form. Therefore, phonologically transparent derivatives, without pronunciation changes from base to derived forms (e.g., artifact, whose pronunciation is the same as the root word FAC) were introduced first, followed by more opaque derived forms (e.g. Anglophile, whose vowel differs from the root word PHIL).

\section{Syllables Treatment}

The eight participants in the control group focused on learning the six syllable types and syllabification (segmenting words into syllables), a more traditional approach to word analysis that is often taught in adult literacy programs (Kruidenier, 2002). Graphic organizers for each set depicted a tree, whose base contained the label of the type of syllable, and the number of syllables, with branches containing the spellings and meanings of four complex words containing at least one example of the featured syllable type. Definitions and sentence contexts were identical to those in the experimental condition. Syllables were defined as "word parts with one beat and one vowel sound". Thus, participants learned the six syllable types, and were encouraged to segment syllables in a flexible way. For example, the first syllable tree featured closed syllables, written in the base of the tree, with the spellings and meanings of four words containing at least one example of closed syllables in the branches: de-flec-tion (the act of bending aside or turning away from proper course); dic-tum (a formal or authoritative statement), ar-ti-fact (an object made by man), and as-ter-isk (a star-shaped character indicating additional information).

For each syllable set, tutors and participants read aloud from scripted slides instructing participants to: View a picture representing the syllable type; View the syllable tree graphic organizer; Copy the graphic organizer in their binders, and Analyze the word's syllables in the following ways: Listen to and repeat the word; Divide the word into syllables, using hyphens (e.g., as-ter-isk whose first 
and last syllables are closed syllables); Underline the syllable that is loudest or has the primary stress placement (e.g., $\underline{a s}$-ter-isk); Scoop out the syllables in the word, using curved underlines; Spell the word; Match the words with their definitions; and Complete sentences using the words.

The sequence for phonological training followed the recommended progression of instruction in syllable types (Wilson, 1996; Moats \& Tolman, 2009): closed; vowel consonant E; open; consonant LE; R-controlled; and double vowel, schwa or odd syllables. After all six syllable types were taught, the instructional sequence progressed from phonologically simpler words (2-3 mixed syllable types) to increasingly complex words (5-6 mixed syllable types).

\section{Fidelity Check}

To check fidelity to treatment, all of which was provided by the primary investigator, sampling of participants' binders was conducted. Two independent evaluators, one masters and one doctoral student, randomly sampled 6 out of 14 of the graphic organizers. After completing a checklist, they found $100 \%$ adherence to the required instructional elements.

\section{Results}

\section{Recruitment, Retention and Randomization of Participants}

Both recruitment and retention of participants were successful. From the $18 \mathrm{GED}$ and ABE students who signed up to participate, 17 of them completed the screening and began the study, while 16 of them completed the study. Every effort was made to provide convenient scheduling and to make up missed sessions. Sixteen of the seventeen participants completed the study.
An independent t-test showed no significant differences between treatment groups after randomization, prior to treatment, including: all scores on the WJ-III; age (each group: $m=23$ years old); education levels: last grade completed (Morphemes $m=$ grade 10.0; Syllables $m=$ grade 9.88); nonverbal intelligence (Morphemes $m=$ 91.75; Syllables $m=93.38$ ); and language learning background (each group: 5 monolingual, 3 bilingual).

\section{Effectiveness of Experimental Intervention and Suitability of Control}

\section{Group Mean Scores}

Figure 2 shows the mean gains scores for the 5 target word measures, including: Target Word Identification; Target Word Analysis; Target Word Spelling; Target Word Definition Matching; and Target Word Sentence Completion. For all measures, the group taught morphemes had measurably greater mean gain scores, with sizable differences for Target Word Analysis and Target Word Identification.

\section{Effect Sizes}

Table 3 shows the mean scores, standard deviations and effect sizes using Cohen's $d$ statistic, which must be interpreted with caution as small sample sizes are likely to yield imprecise effect sizes. For both groups, each target word measures yielded large effect sizes $(d=1.32$ - 4.13), with smaller effect sizes for the WJIII standardized measures. After Morphemes Treatment, small gains were seen on Letter Word ID $(d=.20)$ and Spelling $(d=.24)$, with slight gains for Word Attack $(d=.12)$. After Syllables Treatment, moderate gains were seen for Spelling of Sounds $(d=.67)$, with minimal gains for Word Attack $(d=.12)$ and Spelling $(d=.08)$. Other standardized measures of WJ-III Reading 
Vocabulary and Passage Comprehension yielded either negligible or negative effect sizes.

\section{Individual Responders}

Figure 3 illustrates that at pretest, every participant had significantly reduced reading skills for the Word Attack subtest, except for Participant \#8 who had significantly reduced Passage Comprehension skills.

In accordance with best practice for pilot studies, a threshold of meaningful clinical change was set to indicate which participants had responded favorably to treatment. On any subtest, a gain score of at least one standard score was designated as the threshold for Responders, as this represented one standard deviation from the mean. Figures $4 \mathrm{~A}-\mathrm{F}$ shows the results for Responders on each of the six WJ-III subtests: 1) (Fig. 4A) For Word Attack: Morphemes Treatment $=3$ Responders; Syllables Treatment $=4$ Responders; 2) (Fig. 4B) For Letter Word Identification: Morphemes Treatment $=5$ Responders; Syllables Treatment $=1$ Responder; 3 ) (Fig. 4C) For Spelling: Morphemes Treatment $=5$ responders, Syllables Treatment $=4$ Responders; 4) (Fig. 4D) For Spelling of Sounds: Morphemes Treatment $=4$ Responders; Syllables Treatment $=7$ Responders; 5) (Fig. 4E) For Reading Vocabulary: Morphemes Treatment $=4$ Responders; Syllable Treatment $=1$ Responder; 6) (Fig. 4F) For Passage Comprehension: Morphemes Treatment $=2$ Responders; Syllables Treatment $=3$ Responders.

\section{Discussion}

With low literacy skills directly affecting 90 million adults in America (NRC, 2012) and posing challenges to public health and employment, there is a serious need for more rigorous research on the effects of adult literacy interventions. The current randomized pilot study contributes to the literature on adult literacy interventions and supports prior recommendations to provide morphological instruction for adult struggling readers (Alamprese et al, 2011; Fracasso et al, 2015; Law et al, 2015).

The first question of whether recruitment, randomization, and retention of participants was successful was answered affirmatively. With regard to recruitment, 17 participants were recruited from an adult learning center in New York City. Although participants were reluctant to initiate contact with the primary investigator to begin the study, they were responsive to providing their contact information on a sign-up sheet so that the investigator could initiate contact. With regard to randomization, participants were matched in pairs on reading composite scores (mean grade equivalent on WJ-III Letter Word Identification, Reading Vocabulary and Passage Comprehension), then each pair member was randomly assigned to one of the treatments. A t-test for equality of means revealed no significant differences between the groups for component reading skills (on the WJ-III), age, education level, and language learning background, confirming that randomization had resulted in equivalent groups. With regard to retention, 16 of 17 participants completed the study, a rate considerably higher than other adult literacy studies.

The second question of whether the intervention was effective and its control condition, suitable was answered by comparing group mean scores, effect sizes and individual responders from each group. According to Group Mean Scores, Morphemes Treatment resulted in considerably greater gains for Target Word Analysis, which was expected because only the experimental group learned to extract root words from multimorphemic words. Notably greater gains were also seen for the Morphemes Treatment for Target Word Identification. Greater gains in word 
analysis and word recognition of target words suggest that learning to connect root words and their derived forms was a more effective strategy to increase decoding and word recognition.

Effect sizes must be interpreted with caution as small samples lead to imprecise effect sizes. However, gain scores on all target word measures from both groups were large, suggesting that each intervention resulted in participants effectively learning to analyze, recognize, spell, match definitions and complete sentences for the target words. Small effect sizes were seen on the WJ-III Letter Word Identification and Reading Vocabulary subtests after Morphemes Treatment than after Syllables Treatment. However, for the WJ-III Spelling of Sounds, moderate effect sizes were seen after Syllables Treatment. Notably, each treatment group had the same effect size on the WJ-III Word Attack, suggesting that learning to analyze morphemes and learning to analyze syllables result in similar decoding gains on pseudowords.

To measure Individual Responders (those who responded favorably to treatment), gain scores of at least one Standard Score on any subtest of the WJ-III were set as the threshold for meaningful clinical change. The number of Responders in each group was about the same for Word Attack, Spelling and Passage Comprehension. However, considerably more Responders were seen for the WJ-III Letter Word Identification and for Reading Vocabulary after Morphemes Treatment than after Syllable Treatment. In contrast, more Responders were seen for the WJ-III Spelling of Sounds after Syllable Treatment. Thus, Morphemes Treatment may have served as a more effective strategy for word identification and vocabulary learning, whereas Syllables Treatment may have served as a more effective strategy for learning to spell pseudowords. Overall, learning morphemes increased more individuals' ability to make connections among semantic, phonological and orthographic constituents of words, whereas learning syllables increased more participants' ability to make connections among phonological and orthographic, but not semantic, constituents.

The final question of whether this pilot study demonstrates the potential for a successful full randomized control trial, was answered affirmatively. With favorable recruitment, randomization, and retention, along with acceptable intervention procedures, results demonstrate the potential of this pilot study to be followed by a successful RCT, but with a couple of modifications. First, the assessment measures need to be constructed to align target word measures with standard measures, so that each assessment task reliably measures what it purports to measure. Second, because the intervention and control resulted in similar findings for most measures, the control intervention ought to be changed so that it varies more distinctly from the experimental intervention. For example, the experimental intervention teaching morphemes could be compared to a control intervention teaching whole words rather than sub-lexical word analysis.

\section{Limitations}

Five limitations to this pilot study involved its sample size, group comparisons, word learning contexts, intervention duration and lack of standardized morphology assessments. First, analyses were underpowered with this small sample size. A larger sample might have detected other differences between groups at posttest, perhaps amplifying the vocabulary benefits that the subset of poor coders received after morphological teaching. Second, because both groups were taught word analysis, and made comparable gains in decoding and spelling, it would have been more informative to have had 
a third control group without word analysis. For example, another intervention group could have received vocabulary instruction using the same words, definitions and sentence contexts, but presented as whole words without parsing of morphemes or syllables, to investigate whether word analysis was more powerful than whole word instruction. Alternatively, it would have been beneficial to have included a control group who received only the GED program instruction, without any tutoring in vocabulary and literacy, to serve as an authentic program comparison. Third, morphological teaching may have been even more powerful if new words had been taught within the context of meaningful passages. Similar studies placed morphological instruction within thematic passages with positive results (Kieffer \& Lesaux, 2010; Alamprese, 2011). Fourth, the brief duration of the intervention likely limited the impact of the interventions. While only one month of treatment did result in small gains for certain component literacy skills, lengthier interventions would likely have led to greater treatment outcomes. Finally, the current standardized assessments of morphology (e.g., Foorman, Petscher \& Bishop, 2012; Sabatini, O’Reilly, Halderman \& Bruce, 2014; Sabatini, Bruce, Steinberg \& Weeks, 2015) were not available at the time of the study.

\section{Conclusions and Implications}

To investigate the benefits of morphological instruction in adult literacy, this pilot study provided adult struggling readers with academic vocabulary instruction in either morpheme or syllable analysis. Both groups made very large treatment gains on informal measures of component literacy skills for the target words. The group taught morphemes significantly outperformed the group taught syllables on a standardized test of word recognition. More individuals responded to the treatment after Morphemes Treatment on standardized tests of word recognition and vocabulary. Word recognition skills, when accurate and efficient, enable access to higher level reading skills like vocabulary and comprehension, according to the Lexical Quality Hypothesis (Perfetti \& Hart, 2002; Perfetti, 2007). If the results of this pilot study are replicated in a full RCT, they may corroborate results and recommendations from previous research, including the greater word recognition gains of adult struggling readers after morphological instruction in Alamprese et al's (2011) study.

Further studies are needed to determine which elements of the present study were most effective in teaching literacy to adult struggling readers. It appears that teaching the meanings of bound root words may be beneficial for adults with reading skills at the middle school level, as it is with middle schoolers themselves (Crosson and McKeown, 2016). To increase complex word reading skills in adults, teaching morphemes may be more effective than teaching syllable types, though teaching syllable types may increase phonetic spelling skills. Based on this pilot study, instructional recommendations would be to develop academic vocabulary by explicitly teaching semantic links between root words and their derived forms, to use graphic organizers to organize complex linguistic information in visual form, and to present challenging instructional material to the diverse population of adult struggling readers. 


\section{References}

Adams, C. J. (2015). Scores, test-takers down for new GED exam. Education Week, 34(19), 4.

Alamprese, J., MacArthur, C., Price, C., \& Knight, D. (2011) Effects of a structured decoding curriculum on adult literacy learners' reading development. Journal of Research on Educational Effectiveness, 4, 154-172.

Berninger, V., Nagy, W., Carlisle, J. (2003). Effective treatment for children with dyslexia in grades 4-6: Behavioral and brain evidence. In B. Foorman (Ed.), Preventing and remediating reading difficulties: Bringing science to scale (pp. 381-417). Baltimore, MD: York Press.

Brown, L., Sherbenou, R. \& Johnsen, S. (2010). Test of Nonverbal Intelligence-4 (TONI-4). Austin, TX: PROED

Carlisle, J.F. (2010). Effects of instruction in morphological awareness on literacy achievement: An integrative review. Reading Research Quarterly, 45(4), 464-487.

Chomsky, C. (1970). Reading, writing, and phonology. Harvard Educational Review, 40(2), 287-309.

Chomsky, N., \& Halle, M. (1968). The sound pattern of English. New York: Harper \& Row.

Cohen, J. (1988). Statistical power analysis for the behavioral sciences (2nd ed.). Hillsdale, NJ: Lawrence Erlbaum Associates.

Curtis, M.E. (2006). The role of vocabulary instruction in Adult Basic Education. In J. Comings, B. Garner \& C. Smith (Eds.), Review of adult learning and literacy: Connecting research, policy, and practice. (pp. 43-69). Mahwah, NJ: Lawrence Erlbaum.

Deacon, S. H., Parrila, R., \& Kirby, J. (2006). Processing of derived forms by high-functioning dyslexics. Annals of Dyslexia, 56(1), 103-128.

Duff, D., Stebbins, M.S., Stormont, M., Lembke, E.S., \& Wilson, D.J. (2016). Using curriculum-based measurement data to monitor the effectiveness of the Wilson Reading System for students with disabilities: An exploratory study. International Journal on Disability and Human Development, 15(1), 93-100.
Ehri, L. (1999). Phases of development in learning to read words. In J. Oakhill \& R. Beard (Eds.), Reading development and the teaching of reading: A psychological perspective (pp. 79-108). Oxford: Blackwell.

Ehri, L. (2005). Development of sight word reading: Phases and findings. In M. Snowling \& C. Hulme (Eds.), The science of reading: A handbook (pp. 135-154). Malden, MA: Blackwell Publishing.

Elbro, C., \& Arnbak, E. (1996). The role of morpheme recognition and morphological awareness in dyslexia. Annals of Dyslexia, 46, 209-240.

Foorman, B. R., Petscher, Y., \& Bishop, M. D. (2012). The incremental variance of morphological knowledge to reading comprehension in grades $3-10$ beyond prior reading comprehension, spelling, and text reading efficiency. Learning and Individual Differences, 22(6), 792-798.

Fracasso, L., Bangs, K., \& Binder, K. (2016). The contributions of phonological and morphological awareness to literacy skills in the adult basic education population. Journal of Learning Disabilities, 49(2), 140-151.

Frye, E \& Kress, J. Eds. (2006) The reading teachers' book of lists (5th ed.). Hoboken, NJ: John Wiley \& Sons, Inc.

Goodwin, A. \& Ahn, S. (2010). A meta-analysis of morphological interventions: effects on literacy achievement of children with literacy difficulties. Annals of Dyslexia, 60, 183- 208.

Gray, S., Ehri, L., \& Locke, J. (2018). Morpho-phonemic analysis boosts word reading for adult struggling readers. Reading \& Writing, 31(1), 75-98.

Greenberg, D. (2008). The challenges facing adult literacy programs. Community Literacy Journal, 3, 39-54.

Greenberg, D., Ehri, L., \& Perin, D. (1997). Are wordreading processes the same of different in adult literacy students and third-fifth graders matched for reading level? Journal of Educational Psychology, 89, 262-275. 
Greenberg, D., Wise, J., Morris, R., Fredrick, L., Rodrigo, V., Nanda, A., \& Pae, H. (2011) A randomized control study of instructional approaches for struggling adult readers. Journal of Research on Educational Effectiveness, 4, 101-117.

Herman, J., Gilbert Cote, N., Reilly, L., \& Binder, K. S. (2013). Literacy skill differences between adult native English and native Spanish speakers. Journal of Research and Practice for Adult Literacy, Secondary, and Basic Education, 2(3), 142-155.

Howell, D. (2008) Fundamental statistics for the behavioral sciences (6th ed.). Belmont, CA: Thomas Wadsworth.

Kieffer, M. \& Lesaux, N. (2010) Morphing into adolescents: Active word learning for English-language learners and their classmates in middle school. Journal of Adolescent \& Adult Literacy, 54(1), 47-56.

Kruidenier, J. (2002). Research-based principles for adult basic education: Reading instruction. Washington, DC: National Institute for Literacy.

Law, J., Wouters, J., \& Ghesquiere, P. (2015). Morphological awareness and its role in compensation in adults with dyslexia. Dyslexia, 21, 254-272.

Leon, A. C., Davis, L. L., \& Kraemer, H. C. (2011). The role and interpretation of pilot studies in clinical research. Journal of Psychiatric Research, 45(5), 626-629.

Leong, C. K. (1999). Phonological and morphological processing in adult students with learning/reading disabilities. Journal of Learning Disabilities, 32, 224238.

Mather, N., \& Wendling, B.J., (2011). Essentials of dyslexia assessment and intervention. Hoboken, NJ: John Wiley $\&$ Sons.

McGrew, K.S., Schrank, F.A., \& Woodcock, R.W. (2007). Technical Manual. Woodcock-Johnson III Normative Update. Rolling Meadows, IL: Riverside Publishing.

Moats, L. (2010). Speech to print: Language essentials for teachers (2nd ed.). Baltimore, MD: Brooks.

Nagy, W., Townsend, D. (2012). Words as tools: Learning academic vocabulary as language acquisition. Reading Research Quarterly, 47(1), 91-108.
National Research Council. (2012). Improving adult literacy instruction: Options for practice and research. Washington, DC: National Academies Press.

National Reading Panel. (2000). Teaching children to read: An evidence-based assessment of the scientific research literature on reading and its implications for reading instruction. U.S. Department of Health and Human Services, National Institute of Child Health and Human Development. NIH Pub. No. 00-4769.

Osborne, E. (2003). Vocabulary from Latin and Greek roots: A study of word families (Levels III-VI). Clayton, DE: Preswick House.

Perfetti, C. A. (2007). Reading ability: Lexical quality to comprehension. Scientific Studies of Reading, 11(4), $1-27$.

Perfetti, C. A., \& Hart, L. (2002). The lexical quality hypothesis. In L. Vehoeven, C. Elbro, \& P. Reitsma (Eds.), Precursors of functional literacy. Amsterdam: John Benjamins.

Perin, D., Flugman, B. \& Spiegal, S. (2006). Last chance gulch: Youth participation in urban adult basic education programs. Adult Basic Education, 16(3), 171-188.

Sabatini, J., O'Reilly, T., Halderman, L \& Bruce, K., (2014). Integrating scenario-based and component reading skill measures to understand the reading behavior of struggling readers.. Learning Disabilities Research \& Practice, 29(1), 36-43.

Sabatini, J., Bruce, K., Steinberg, J., \& Weeks, J. (2015). SARA reading components tests, RISE forms: Test design and technical adequacy, 2nd Edition (Research Report No. RR-15-32). Princeton, NJ: ETS.

Sabatini, J., Shore, J., Holtzman, S., Scarborough, H. (2011). Relative effectiveness of reading intervention programs for adults with low literacy. Journal of Research on Educational Effectiveness, 4,118-133.

Stanovitch, K. E., \& Siegel, L. S. (1994). Phenotypic performance profile of children with reading disabilities: A regression-based test of the phonological-core variable-difference model. Journal of Educational Psychology, 86, 24-53. 
Tighe, E. L. \& Binder, K. S. (2015). AN investigation of morphological awareness and processing in adults with low literacy. Applied Psycholinguistics, 36, 245-273.

Tighe, L., \& Schnatschneider, C. (2016). Examining the relationships of component reading skills to reading comprehension in struggling adult readers: A metaanalysis. Journal of Learning Disabilities, 49, 395-409.
Venezky, R. L. (1999). The American way of spelling: The structure and origins of American English orthography. New York, NY: Guilford.

Woodcock, R.W., McGrew, K.S., \& Mather, N. (2001, 2007). Woodcock-Johnson III Tests of Achievement. Rolling Meadows, IL: Riverside Publishing. 
TABLE 1. Means, Standard Deviations, Gain Scores and Effect Sizes* for Target Word Measures and Standardized Measures

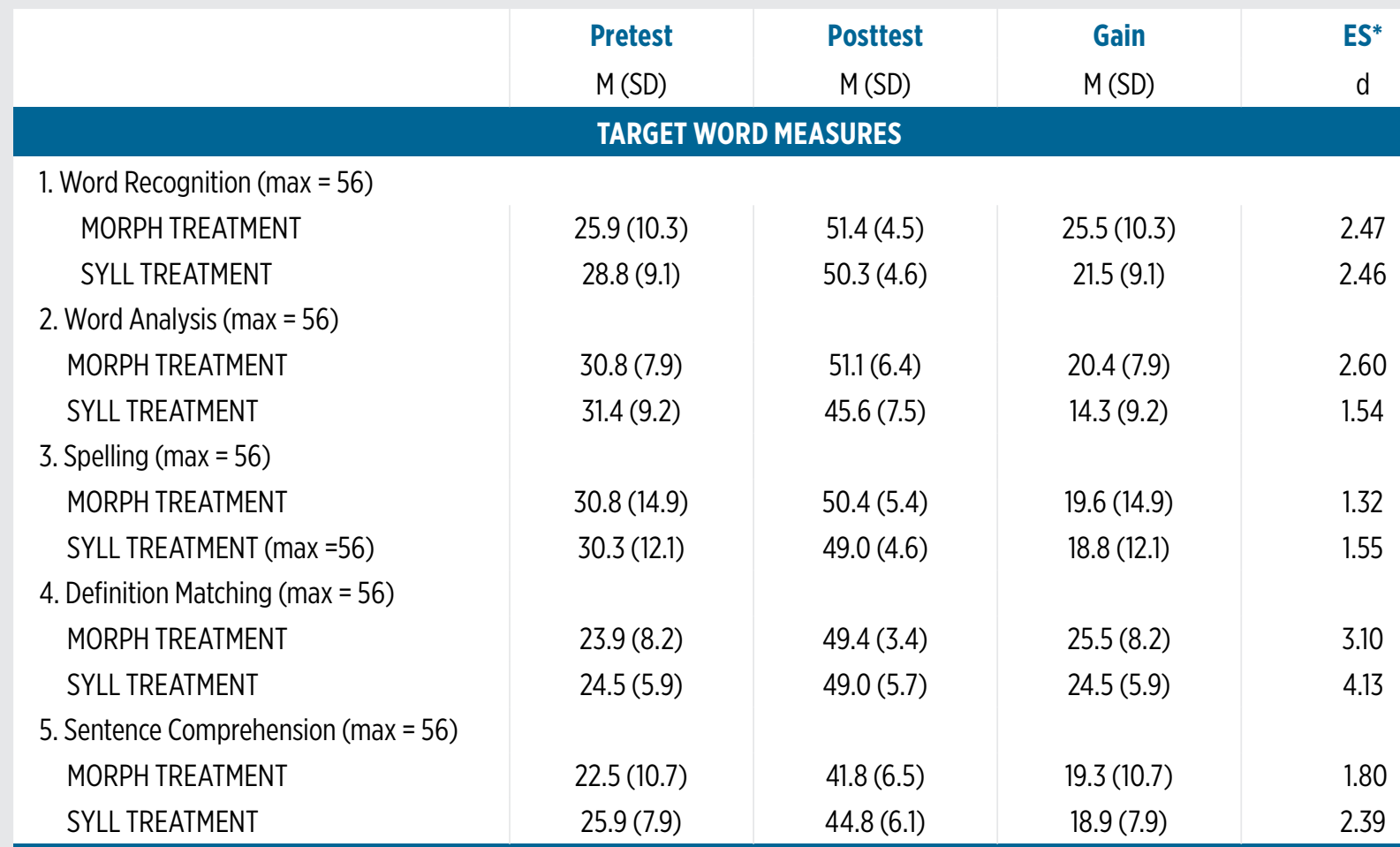

\section{STANDARDIZED MEASURES (WJ-III Standard Scores)}

1. WJ-III Letter Word ID

MORPH TREATMENT

SYLL TREATMENT

2. WJ-III Word Attack

MORPH TREATMENT

SYLL TREATMENT

3. WJ-III Spelling

MORPH TREATMENT

SYLL TREATMENT

4. WJ-III Spelling of Sounds

MORPH TREATMENT

SYLL TREATMENT

5. WJ-III Reading Vocabulary

MORPH TREATMENT

SYLL TREATMENT

60 WJ-III Passage Comprehension
$85.6(6.3)$

$84.4(6.3)$

$82.4(9.6)$

$79.8(9.7)$

$86.5(13.0)$

$86.1(7.8)$

$85.8(10.7)$

$79.4(6.7)$

$83.8(5.4)$

$84.9(3.8)$

$88.0(5.2)$

$87.1(3.0)$
$86.9(6.8)$

$82.9(8.1)$

$83.5(9.2)$

$80.9(10.9)$

$89.6(10.8)$

$86.8(5.8)$

$85.6(8.9)$

$83.9(6.1)$

$83.4(7.6)$

$82.1(4.9)$

$86.5(5.6)$

$85.8(6.2)$
$1.3(6.3)$

$-1.5(2.4)$

.20

$-.23$

$1.1(9.6) \quad .12$

$1.1(9.7)$

.12

39

\begin{tabular}{|l|l|l|l|l|}
\hline MORPH TREATMENT & $88.0(5.2)$ & $86.5(5.6)$ & $-1.5(5.2)$ & -.29 \\
\hline SYLL TREATMENT & $87.1(3.0)$ & $85.8(6.2)$ & $-1.4(3.0)$ & -.46 \\
\hline
\end{tabular}

*Effect sizes must be interpreted with caution, as small sample sizes are likely to produce imprecise effect sizes. All effect sizes were calculated as Cohen's $d$ (Cohen, 1988), using the formula: $\{d=m$ after $-m$ before/ standard deviation of pretest $\}$ because the pretest SD is more meaningful than that of the difference scores or pooled SD, as it is in the units of the original measurements (Howell, 2008). 


\section{FIGURE 1: Graphic Organizer for Root Word Trees*}

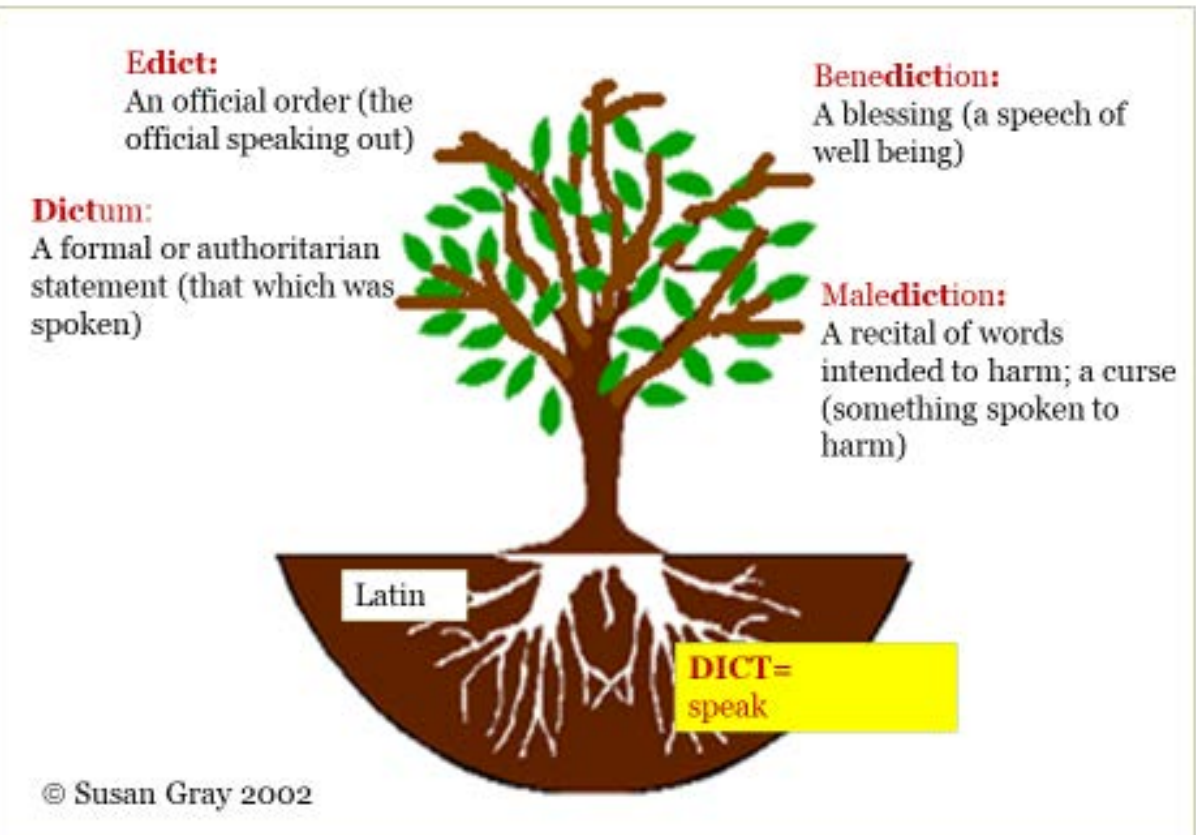
${ }^{*}$ Meanings of root words were explicitly linked to meanings of their derived forms (root related words). In the example, each definition of derived words contains a form of the word SPEAK (edict= the official speaking out; benediction= a speech of well-being; dictum= that which was spoken; malediction= something spoken to harm), linking them to the meaning of their root word DICT meaning "SPEAK".

\section{Set 8}

FIGURE 2. The group taught morphemes surpassed the group taught syllables for gain scores on each target word measure, including 1) Word Identification, 2) Word Analysis, 3) Spelling, 4) Definition Matching, and 5) Sentence Completion.

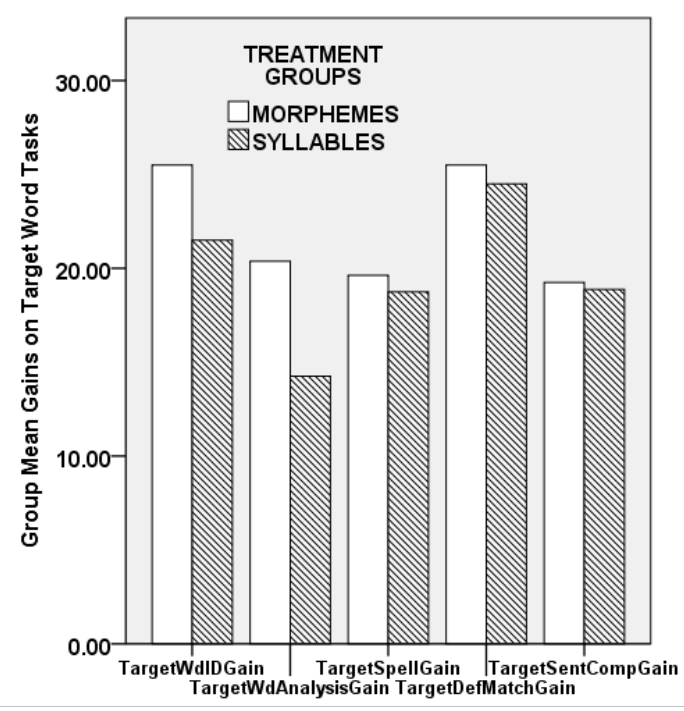

FIGURE 3. A-B. At pretest, every participant had significantly reduced decoding skills on the WJ-III Word Attack subtest except participant number 8 , whose primary difficulty was in reading comprehension, estimated to be 6 th grade equivalency level.

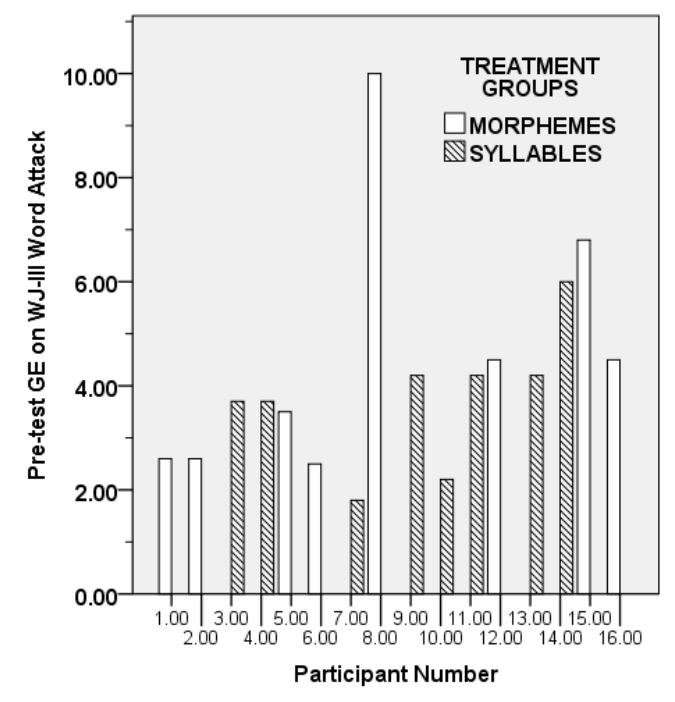


FIGURES 4 A-F. Participants who made at least one SS gain on any WJ-III literacy subtest were labeled as "Responders" who had responded to treatment with clinically meaningful gains.
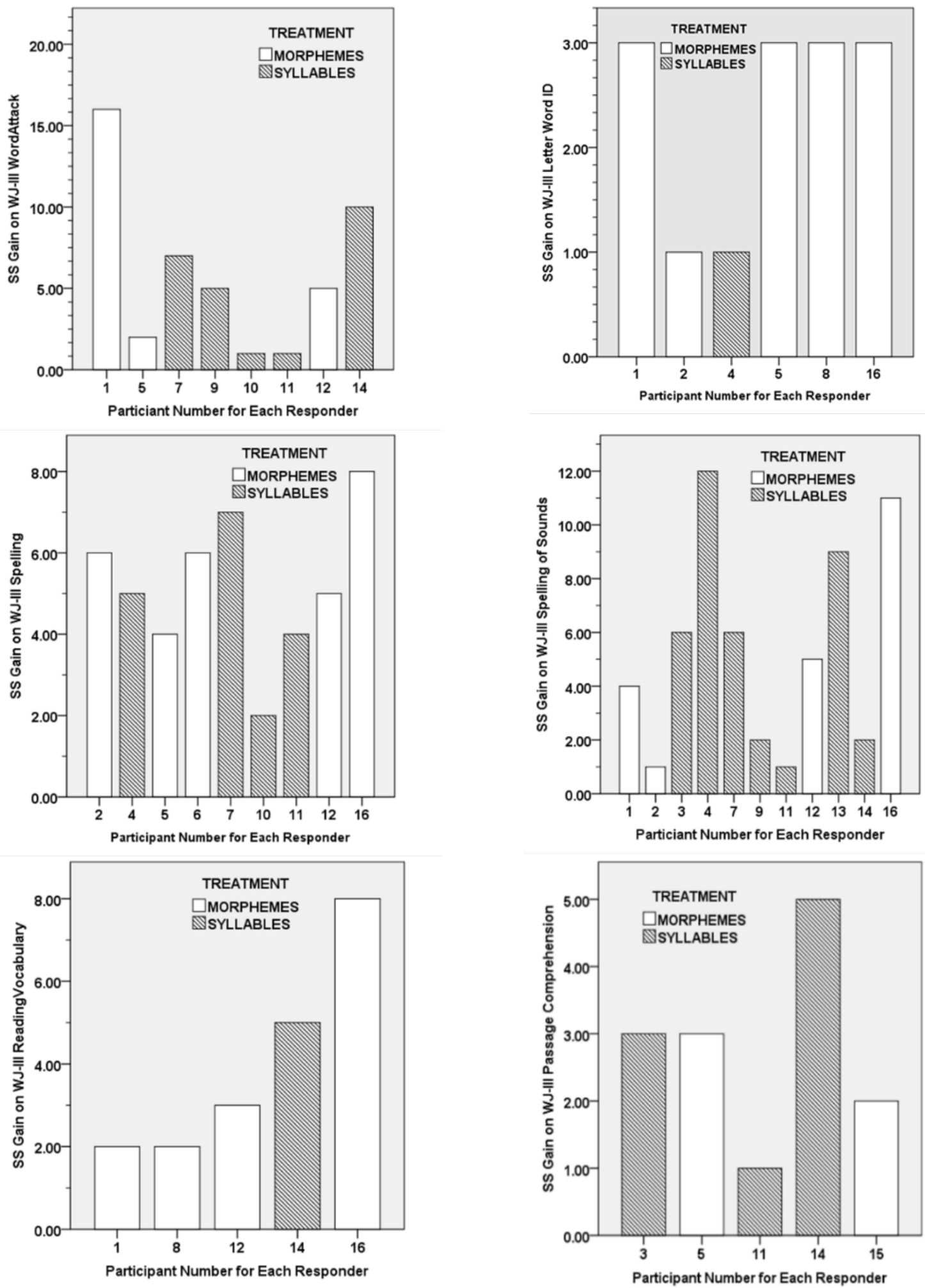


\section{Appendix 1: Latin/Greek Root Word Tree Sets}

\begin{tabular}{l|l|l|l|l|l}
\hline Root Word & Meaning & Derived Form & Derived Form & \multicolumn{1}{|c|}{ Derived Form } & \multicolumn{1}{|c|}{ Derived Form } \\
\hline fic/fac & make & artifact & fictitious & facsimile & malefactor \\
mov/mot & move & motif & emote & motivate & immovable \\
ast & star & asterisk & astronomical & astrological & astrophysicist \\
dict & say & edict & dictum & benediction & malediction \\
scrib/scrip & write & postscript & ascribe & prescriptive & circumscribe \\
flec/flex & bend & flexor & deflection & inflexible & inflectional \\
geo & earth & geode & geocentric & geochemistry & geologist \\
clam/claim & shout & declaim & exclamatory & clamorous & acclamation \\
cred & believe & credible & incredulous & credence & credulity \\
chron & time & chronicle & chronological & anachronism & synchronous \\
vol/volv & roll, turn & evolve & voluble & convoluted & devolution \\
port & carry & portly & comportment & purported & importunate \\
bio & life & biome & autobiography & antibiotic & biosphere \\
phil & love & philter & philanthropist & philanderer & Anglophile
\end{tabular}

